\title{
Cocaine Alters the Daily Activity Patterns of Adult SD Female Rats
}

\author{
Min J. Lee, Nachum Dafny* \\ Department of Neurobiology and Anatomy, The University of Texas-Medical School at Houston, Houston, \\ Texas, USA \\ Email: "nachum.dafny@uth.tmc.edu
}

Received 15 September 2014; revised 1 November 2014; accepted 16 November 2014

Copyright @ 2014 by authors and Scientific Research Publishing Inc.

This work is licensed under the Creative Commons Attribution International License (CC BY).

http://creativecommons.org/licenses/by/4.0/

(c) () Open Access

\section{Abstract}

The effects of chronic cocaine administration on the locomotor rhythmic patterns of adult female Sprague-Dawley (SD) rats were recorded using an open-field testing assay. The animals were divided into four groups, control (saline), $3.0 \mathrm{mg} / \mathrm{kg}, 7.5 \mathrm{mg} / \mathrm{kg}$, and $15.0 \mathrm{mg} / \mathrm{kg}$ i.p. cocaine group respectively. On experimental day (ED 1), all animals were treated with saline. On ED 2 to ED 7, either saline or cocaine $(3.0,7.5$, or $15.0 \mathrm{mg} / \mathrm{kg}$ i.p.) was given followed by three days of no treatment (ED 8 to ED 10). On ED 11, rats were treated as they were on ED 2 to ED 7, i.e. either saline, $3.0,7.5$, or $15.0 \mathrm{mg} / \mathrm{kg}$ i.p. cocaine. The locomotor activities of rats were recorded for $23 \mathrm{hours}$ daily, allowing one hour for the animal handling and injections, using open field cages with 16 infrared beams of motion detectors. Any breakages of these beams due to the movement of the animals were recorded and compiled by a computer and analyzed. It was observed that all three doses of repeated cocaine administration $(3.0 \mathrm{mg} / \mathrm{kg}, 7.5 \mathrm{mg} / \mathrm{kg}$, and $15.0 \mathrm{mg} / \mathrm{kg}$ i.p. cocaine) significantly alter the locomotor rhythmic activity patterns of the adult female SD rats, which suggest that repeated cocaine exposure modulates body homeostasis.

\section{Keywords}

Psychostimulant, Circadian Activity Diurnal, Behavior, Locomotor Activity, Chronic Cocaine

\section{Introduction}

Cocaine has been a consistently abused drug. It is estimated that about 3 million people in the USA chronically abuse cocaine, and currently there are no treatments available despite extensive research [1]. Like other drugs of abuse, such as amphetamine, cocaine influences clock genes and clock genes are also involved in the action of

\footnotetext{
"Corresponding author.
} 
cocaine [2]-[4].

The physiology of behaviors of living organisms is under circadian activity rhythms and controlled by endogenous biological clock that modulates its response to daily environmental cues [5]-[8]. Numerous central and peripheral biological clock genes are kept in sync to each other by a master clock, the suprachiasmatic nucleus (SCN) located in the anterior hypothalamus area which is considered as the master clock [8]-[10]. Projections from the light-sensitive retinal ganglion cells to the SCN via the retino-hypothalamic tract synchronize the rhythm of the SCN to the day-night cycle [11] [12]. The SCN, with other biological clocks, maintains body homeostasis by regulating physiological and biological processes, such as the sleep-wake cycle, locomotor activity, blood pressure, and more [8] [13]. Disturbances in such circadian activity rhythm patterns are associated with behavioral and physiological disorders.

Clock gene activities are modified by increased or decreased transcriptions of genes encoding proteins like Per and Cry, which normally express diurnal rhythms that are the basis for the generation of the SCN rhythms [9] [14]-[17]. These genes are susceptible to various pharmacological agents that are capable of changing the amplitude or phase of the circadian pacemaker resulting in homeostasis alteration [5]. Our hypothesis is that change in diurnal activity pattern, as a result of drug exposure is an experimental marker to indicate that the drug alters the mechanism regulating the biological clock, i.e., the clock gene, and that clock gene alteration may indicate that the drug exerts a long lasting effect far beyond the cessation of drug intake.

The most prominent behavioral effect of psychostimulant administration in rodents is the augmentation or attenuation of locomotor activity following repetitive psychostimulant administration compared to the initial effect of the drug. This phenomenon has been referred to as behavioral sensitization or tolerance, respectively [18] [19]. The open field assay, which represents the interaction of the subject with the experimental environment, was a widely used method of studying animal behavior [20]-[22]. Therefore, in the present study, the open field assay was used to record the locomotor activity pattern over a prolonged period of time (eleven days non-stop) to assess the effect of cocaine on locomotor circadian activity pattern.

\section{Methods}

\subsection{Animals}

Forty eight young adult, postnatal day 56 (P-56) to P-58 female Sprague-Dawley rats, weighing 170 - $180 \mathrm{~g}$ upon arrival, were acquired from Harlan, Indianapolis, IN, USA. Rats arrived in multiple shipments and were housed individually in a cage that became their test cage in the sound proof experiment room on a 12:12 night/ dark cycle (lights on at $06: 00$ ) at an ambient temperature of $21^{\circ} \mathrm{C} \pm 2^{\circ} \mathrm{C}$ and relative humidity of $37 \%-42 \%$. Food pellets and water were provided ad libitum to the animals. After 5 to 7 days of acclimation, animals were weighed and randomly divided into four groups, control $(n=12), 3.0 \mathrm{mg} / \mathrm{kg}$ i.p. cocaine $(\mathrm{n}=12), 7.5 \mathrm{mg} / \mathrm{kg}$ i.p. cocaine $(\mathrm{n}=12)$, and $15 \mathrm{mg} / \mathrm{kg}$ i.p. cocaine $(\mathrm{n}=12)$ groups, and placed back in their open field testing/home cages $(40.5 \times 40.5 \times 31.5 \mathrm{~cm})$ in the same room. An additional acclimation period of 24 to 36 hours was followed by 11 consecutive recording days (Table 1 ). All effort was made to minimize the number of animals used and their suffering. The experimental protocol was approved by our animal welfare committee.

\subsection{The Open Field Apparatus}

Locomotor activity was recorded using the computerized animal activity monitoring (CAAM; AccuScan In struments, Inc., Columbus, $\mathrm{OH}$ ) system. During eleven non-stop recording days, the recordings were stopped

Table 1. The treatment and the experimental protocol for each of the 4 animal groups.

\begin{tabular}{cccccc}
\hline & Groups & ED 1 & ED 2 -7 & ED 8 - 10 & ED 11 \\
\hline 1 & Control & Saline & Saline & Washout & Saline \\
2 & $3.0 \mathrm{mg} / \mathrm{kg}$ cocaine & Saline & $3.0 \mathrm{mg} / \mathrm{kg}$ cocaine & Washout & $3.0 \mathrm{mg} / \mathrm{kg}$ cocaine \\
3 & $7.5 \mathrm{mg} / \mathrm{kg}$ cocaine & Saline & $7.5 \mathrm{mg} / \mathrm{kg}$ cocaine & Washout & $7.5 \mathrm{mg} / \mathrm{kg}$ cocaine \\
4 & $15.0 \mathrm{mg} / \mathrm{kg}$ cocaine & Saline & $15.0 \mathrm{mg} / \mathrm{kg}$ cocaine & Washout & $15.0 \mathrm{mg} / \mathrm{kg}$ cocaine \\
\hline
\end{tabular}

ED: experimental day; All injections were i.p. and equalized to volume of $0.8 \mathrm{cc} / \mathrm{animal}$ and were given at 07:00. 
only for animal handling between 06:30 and 07:00. The sound-proof experimental room was closed during all other hours and the animals were not disturbed. The 12 open field cages each had two levels of 16 infrared beams and their sensors consisted of the CAAM system. The interruptions of these beams were counted and compiled by AccuScan Analyzer and downloaded to PC every 10 minutes. Then OASIS software organized these data into several different locomotor movement indices, such as total distance traveled and horizontal and stereotypic activities [7] [20] [23]-[27].

\subsection{Drugs}

Cocaine was dissolved in $0.9 \%$ isotonic saline solution $(0.9 \% \mathrm{NaCl})$. All the injections were of the same volume $(0.8 \mathrm{cc})$ to insure that different responses were not due to differences in injection volumes. Injections were made intra-peritoneal (i.p.) between 06:30 and 07:00.

\subsection{Procedure}

On experimental day 1 (ED 1) (baseline control data), all groups were given a single injection of $0.8 \mathrm{ml}$ of $0.9 \%$ $\mathrm{NaCl}$ solution, and the recording started immediately after injection, approximately at 07:00. On ED 2 to 7, animals received a single injection daily of either; saline, $3.0 \mathrm{mg} / \mathrm{kg}$ cocaine, $7.5 \mathrm{mg} / \mathrm{kg}$ cocaine, or $15.0 \mathrm{mg} / \mathrm{kg}$ cocaine depending on the group assignments (Table 1). EDs 8 to 10 were the washout period, and the locomotor activity was recorded without any injection. A single re-challenge injection, of identical dose as given in ED 2 through 7, followed on ED 11 (Table 1). Locomotor activity was recorded nonstop for 11 days with animal handling occuring each day. The experiment procedures conformed to the guidelines of NIH and the declaration of Helsinki and approved by our local Animal Welfare Committee. In preliminary experiments four female rats were kept together in one cage from P40 to P80 with the intention that all the female rats would cycle on the same day. Vaginal smears [28] were taken daily prior to daily psychostimulant injections. It was found that the drug treatment did not alter the estrous cycle. Thus, all the experimental groups started in the proestrous day and lasted for 11 days, i.e., about three estrous cycles.

\subsection{Data Analysis}

Two data analyses were used. 1) Six 10 min recording bins were summed and averaged to produce hourly histograms with standard errors. They showed 24-hour activity for each locomotor index, horizontal activity (HA), total distance (TD) traveled, and number of stereotypy (NOS); 2) The same 10 min counts/bins were used as plotting points for statistical calculation using the cosine curve statistical analysis (CCSA) test [29], which is a test that examines whether circadian activity pattern is significantly altered between the two experimental days (EDs) being compared. The CCSA test fit the data points of each recording point into a cosine curve and estimated three parameters, mesor (average activity level), amplitude (distance from mesor to highest point), and acrophase (time at which the maximum amplitude occurs) in order to more accurately model the cyclic nature of the activity over a 24-hour cycle. These three components were used to determine whether locomotor activity diurnal rhythm pattern has been significantly altered [29]. There was a dose dependent increase in locomotor activity immediately after the cocaine injection. This effect was profound and lasted as long as three hours. This immediate increase in locomotion as a response to the injection skewed the statistical parameterization of the CCSA test, as the data points were poorly fit using a cosine curve. Therefore, in order to account for the immediate effect of the drug and to create a statistically appropriate cosine curve, the initial three hours of the locomotor activity after the injection were eliminated. To maintain consistent parameterization and analysis of the protocol all subsequent calculation were based on the removal of the first three hours after cocaine exposure. Since the focus of this study is on the activity pattern of the whole day and not the immediate effect post-injecttion, the first three hours of the data after the cocaine injections were excluded in the CCSA analysis for all groups.

To analyze the data, four comparisons were made: 1) Acute effect-compared the activity of ED 1 (control recording with saline) with activity of ED 2 (the first day of cocaine injection) to observe whether a single (acute) injection is able to change the locomotor diurnal rhythm activity pattern; 2) Induction phase-comparison of the activity of EDs 1 against the activity obtained on ED 7 (the last day of the drug maintenance treatments; Table 1) to observe whether the six days of treatments induce changes in activity pattern; 3) Washout phase-comparison between activity of ED 1 to activity of EDs 8, 9, and 10 to observe whether the activity alterations induced dur- 
ing the maintenance period persists in absence of daily cocaine injections (Table 1); and 4) Expression phasecomparison of the activity obtained on EDs 1 with the activity of ED 11 (i.p. cocaine re-challenge) to observe whether the chronic treatment elicits a long lasting effect; only the HA index was discussed in this paper, because all the other locomotor indices exhibited similar findings.

\section{Results}

\subsection{Control}

Figure 1 shows the control group's (rats treated with saline on ED 1 to ED 7 and ED 11) hourly histogram and the superimposed graphs of the temporal 10 minutes counts/bin of horizontal activity (HA) for experimental days (EDs) 1, 2, 7, 8, and 11. As reported in previous studies, rats treated with saline only showed increases in activity during first few minutes post injection and then the activity levels returned to baseline [7] [20]. The diurnal HA rhythm pattern stayed similar with minor non significant fluctuations throughout the 11 experimental days period. The CCSA test comparing the activity pattern of ED 1 with ED 2 to ED 11 indicated no significant changes in diurnal HA patterns between these EDs. Figure 1 and Table 2 show the histogram and the CCSA test data for ED's 1, 2, 7, 8, and 11. Other locomotor indices also yielded similar results (not all graphs are shown). Since every new shipment of rats exhibit different baseline activity, and based on the saline control observation that all the day exhibit similar activity pattern as ED1, any significant differences using the CCSA test between the data of saline ED 1 and other EDs of cocaine treated days can and was considered as the drug effects.

\subsection{Acute Effect: Comparing ED 1 vs. ED 2}

Figure 2 shows the hourly histogram of ED 1 and ED 2 and the CCSA test graph for HA index of $7.5 \mathrm{mg} / \mathrm{kg}$ cocaine group. There were increases in the first three hours post injection, but the activity levels were decreased throughout the rest of ED 2. The CCSA test indicated that acute cocaine injection induced significant changesin the HA patterns between ED 2 and ED 1 (Table 3). Asimilar observation was obtained from the $15.0 \mathrm{mg} / \mathrm{kg}$ i.p. cocaine group. However, the $3.0 \mathrm{mg} / \mathrm{kg}$ i.p. cocaine group, in the CCSA test, did not show any significant changes in locomotor circadian rhythms between ED 1 and ED 2 for any of the indices compared (Table 3).

\subsection{Induction Phase: Comparing ED 1 vs. ED 7}

The hourly HA histograms and the corresponding temporal graph of the CCSA test of the $7.5 \mathrm{mg} / \mathrm{kg}$ cocaine

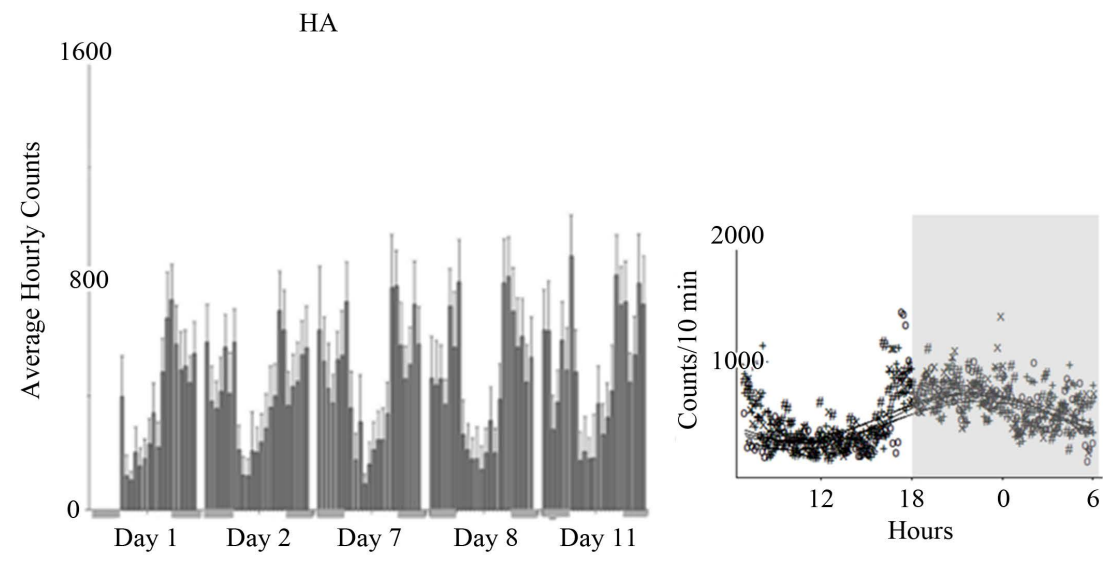

Figure 1. Control group. The hourly histogram of HA and superimposed cosine curve statistical analysis (CCSA) graph of EDs 1, 2, 7, 8, and 11 are displayed. Each symbol represents different EDs, i.e., " $\mathrm{x}$ " represents ED 1 . Similar diurnal activity patterns with minor insignificant fluctuation are seen throughout the EDs. Similar results were observation in TDT and NOS as well. Shaded areas under the histograms indicate dark periods of the experimental period; experimental day 1 begins at 07:00 h whereas all the other days thereafter began at 00:00 h. The cocaine curve is composed from counts per 10 minutes. 
Table 2. Statistic calculation using the cosine curve statistical analysis (CCSA) for the control group comparing across all experimental days.

\begin{tabular}{|c|c|c|c|c|c|c|c|}
\hline \multirow{2}{*}{ COMPARISON } & \multirow{2}{*}{$\mathbf{L I}$} & \multicolumn{2}{|c|}{ Mesor } & \multicolumn{2}{|c|}{ Amp } & \multicolumn{2}{|c|}{ Acrotime } \\
\hline & & F-statistics & $P$-values & F-statistics & $P$-values & F-statistics & $P$-values \\
\hline \multirow{3}{*}{$\begin{array}{c}\text { All days } \\
(1,2,7,8,11)\end{array}$} & HA & $1.209(4,680)$ & 0.305 & $1.428(4,680)$ & 0.223 & $1.561(4,680)$ & 0.183 \\
\hline & $\mathrm{TD}$ & $0.923(4,680)$ & 0.450 & $2.021(4,680)$ & 0.090 & $1.938(4,680)$ & 0.102 \\
\hline & NOS & $1.719(4,680)$ & 0.144 & $0.151(4,680)$ & 0.963 & $1.198(4,680)$ & 0.310 \\
\hline
\end{tabular}

Significance was set at $P<0.05$. LI: locomotor index; Mesor: mean level of cosine curve; Amp: amplitudeheight of the peak above the mean level; Acrotime: time at which peak occurs; Comparing all the experimental days of control group shows no significant change in circadian rhythm throughout the experiment, i.e. activity obtained on ED 1 following saline was similar to that obtained on ED 2, 7, 8, and 11.

Table 3. The statistical calculation using the CCSA test for all the cocaine groups comparing between different experimental days.

\begin{tabular}{|c|c|c|c|c|c|}
\hline Contrast & LI & Drug Conc. (mg/kg) & Characteristic & F-statistic & $P$-value \\
\hline \multirow{6}{*}{ Day 1 vs. 2} & & 7.5 & Mesor & $25.01(1,254)$ & 0.000 \\
\hline & HA & 15.0 & Mesor & $4.187(1,254)$ & 0.042 \\
\hline & TD & 7.5 & Mesor & $4.485(1,254)$ & 0.020 \\
\hline & & 3.0 & Amplitude & $6.57(1,254)$ & 0.011 \\
\hline & NOS & & Mesor & $8.544(1,254)$ & 0.004 \\
\hline & & 7.5 & Amplitude & $4.358(1,254)$ & 0.038 \\
\hline \multirow{16}{*}{ Day 1 vs. 7} & & 3.0 & Amplitude & $8.119(1,254)$ & 0.005 \\
\hline & & & Mesor & $30.88(1,254)$ & 0.000 \\
\hline & & 7.5 & & & \\
\hline & HA & & Amplitude & $6.688(1,254)$ & 0,010 \\
\hline & & & Mesor & $14.75(1,254)$ & 0.000 \\
\hline & & & Acrotime & $25.27(1,254)$ & 0.000 \\
\hline & & & Mesor & $5.235(1,254)$ & 0.023 \\
\hline & & 3.0 & Amplitude & $13.04(1,254)$ & 0.000 \\
\hline & TD & 7.5 & Acrotime & $5.634(1,254)$ & 0.018 \\
\hline & & 15.0 & Acrotime & $15.38(1,254)$ & 0.000 \\
\hline & & & Amplitude & $5.781(1,254)$ & 0.017 \\
\hline & & 3.0 & Acrotime & $3.948(1,254)$ & 0.048 \\
\hline & NOS & 7.5 & Mesor & $11.33(1,254)$ & 0.001 \\
\hline & & & Mesor & $7.346(1,254)$ & 0.007 \\
\hline & & 15.0 & & & \\
\hline & & & Acrotime & $9.7(1,254)$ & 0.002 \\
\hline
\end{tabular}




\section{Continued}

\begin{tabular}{|c|c|c|c|c|c|}
\hline & & & Amplitude & $5.968(1,254)$ & 0.015 \\
\hline & & & Acrotime & $7.17(1,254)$ & 0.008 \\
\hline & & & Mesor & $7.285(1,254)$ & 0.007 \\
\hline & HA & 7.5 & Amplitude & $16.51(1,254)$ & 0.000 \\
\hline & & & Acrotime & $9.074(1,254)$ & 0.003 \\
\hline & & & Mesor & $10.33(1,254)$ & 0.001 \\
\hline & & & Acrotime & $9.84 \quad(1,254)$ & 0.002 \\
\hline & & & Amplitude & $6.223(1,254)$ & 0.013 \\
\hline Day 1 vo. & & 3.0 & Acrotime & $4.174(1,254)$ & 0.042 \\
\hline & TD & & Amplitude & $5.227(1,254)$ & 0.023 \\
\hline & & & Acrotime & $9.614(1,254)$ & 0.002 \\
\hline & & 15.0 & Acrotime & $13.39(1,254)$ & 0.000 \\
\hline & & 3.0 & Acrotime & $6.433(1,254)$ & 0.012 \\
\hline & & 7.5 & Acrotime & $5.181(1,254)$ & 0.024 \\
\hline & & & Mesor & $8.941(1,254)$ & 0.003 \\
\hline & & & Acrotime & $11.13(1,254)$ & 0.001 \\
\hline & & 3.0 & Acrotime & $5.258(1,254)$ & 0.023 \\
\hline & & & Mesor & $5.982(1,254)$ & 0.015 \\
\hline & & 7.5 & Amplitude & $11.95(1,254)$ & 0.001 \\
\hline & & & Acrotime & $6.854(1,254)$ & 0.009 \\
\hline & & & Mesor & $5.765(1,254)$ & 0.017 \\
\hline & & & Acrotime & $28.05(1,254)$ & 0.000 \\
\hline & & 30 & Amplitude & $10.4(1,254)$ & 0.001 \\
\hline Day 1 vs. 11 & & & Acrotime & $4.537(1,254)$ & 0.034 \\
\hline & ID & 7.5 & Acrotime & $5.981(1,254)$ & 0.015 \\
\hline & & 15.0 & Acrotime & $15.09(1,254)$ & 0.000 \\
\hline & & 3.0 & Acrotime & $5.679(1,254)$ & 0.018 \\
\hline & & & Mesor & $10.28(1,254)$ & 0.002 \\
\hline & NOS & 1.5 & Acrotime & $9.235(1,254)$ & 0.003 \\
\hline & & & Mesor & $6.575(1,254)$ & 0.011 \\
\hline & & 10.0 & Acrotime & $20.82(1,254)$ & 0.000 \\
\hline
\end{tabular}

Significance was set at $P<0.05$. Gray highlighted field indicates the significant changes between the two compared experimental days. Only the results with significant differences were shown. LI: locomotor indicess; Mesor: mean level of cosine curve; Amp: amplitude-height of the peak above the mean level; Acrotime: time at which peak occurs. 


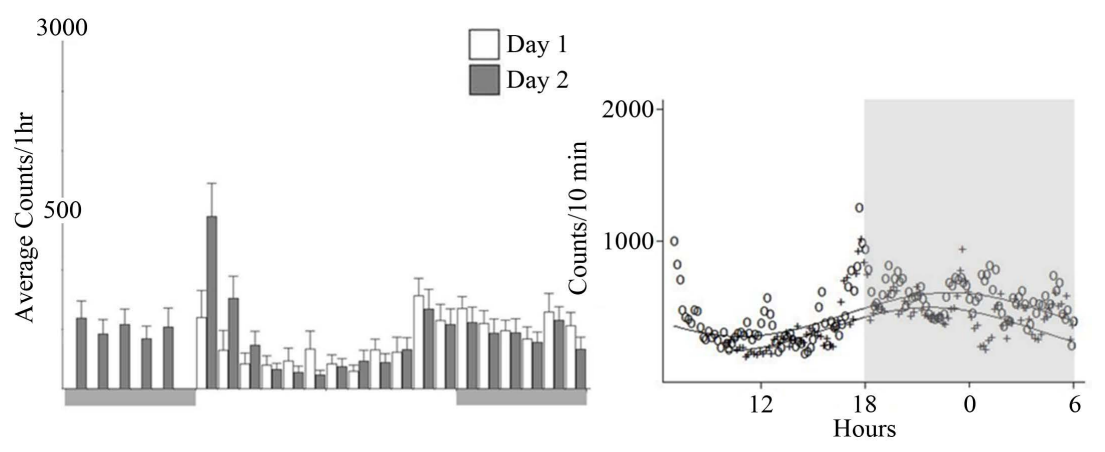

Figure 2. The hourly histogram of ED 1 and ED 2 and the CCSA test graph for HA index of $7.5 \mathrm{mg} / \mathrm{kg}$ cocaine group are shown. ${ }^{\circ}$ symbol represents ED 1 and + symbol represents ED 2 in the CCSA graphs.

group comparing ED 7 to ED 1 are displayed in Figure 3. As with the comparison between EDs 1 and ED 2, there were increases in locomotor activity in the first two to three hours post cocaine injection. The HA was increased in some hours of the dark phase and decreased during some hours of light and dark phase. The CCSA test comparing the activity levels post cocaine injection on ED 7 with ED 1 indicated significant differences between the diurnal rhythm patterns in the two EDs (Table 3). Similar findings were recorded for the other two cocainedos age groups as well (Table 3).

\subsection{Washout Phase: Comparing ED 1 vs. ED 8, 9 and 10}

Figure 4 is similar to Figure 3 but describes the comparison between the data of ED 1 and ED 8, of these groups (3.0; 7.5; and $15.0 \mathrm{mg} / \mathrm{kg}$ cocaine) the first washout day (Table 1). There were some increases in locomotor activity during dark phase on ED 8 compared to ED 1. These fluctuations in activities resulted in significant changes between the diurnal rhythms of ED 1 and 8, according to the CCSA test (Table 3). Similar findings were recorded for other dosage groups as well (Table 3) and at ED 9 and 10 (data not shown).

\subsection{Expression Phase: Comparing ED 1 vs. ED 11}

Figure 5 compares the data of ED 1 to that of ED 11 for $7.5 \mathrm{mg} / \mathrm{kg}$ cocaine group. The figure shows that following cocaine injection on ED 11, there are increases in locomotor activity in the first two to three hours of light phase and during some hours of the dark phase. These changes resulted in significantly altered diurnal rhythm on ED 11 compared to ED 1 according to the CCSA test (Table 3). Similar findings were recorded for other dosage groups as well (Table 3).

\section{Discussion}

It has been shown that the acute administration of cocaine induces increased locomotor activity immediately after its injection [30]-[32], and repeated cocaine administration, especially of moderate doses, produces further progressive enhancement of locomotor activity, comparing to the initial effect i.e. expression of behavioral sensitization [31] [33] [34]. It is currently thought that cocaine elicits its behavioral effect by blocking dopamine transporter and, thus, inhibiting the reuptake of dopamine (DA) into the synaptic terminal and increasing the concentration of synaptic DA concentration [35]. This increased DA concentration activates D1 and D2 receptors, which activates different signal cascades and transcription factors that synergistically work to achieve locomotor cocaine effects and behavioral sensitization [36]-[41]. Our observation confirms the above results that repetitive cocaine administration elicits behavioral sensitization. However, the focus of this study was on the effects of cocaine on the daily locomotor activity pattern and not the immediate effect after cocaine exposure.

There is evidence to suggest that acute and chronic effects of cocaine are influenced by different sets of clock genes [42]. The present study, however, indicates that this relationship between circadian rhythm and cocaine sensitization also works the other way as well, i.e. chronic administration of cocaine alters the locomotor diurnal activity pattern of SD female rats. In this study, female adult SD rats were administered daily with either; saline (control group), $3.0 \mathrm{mg} / \mathrm{kg}$ i.p. cocaine, $7.5 \mathrm{mg} / \mathrm{kg}$ i.p. cocaine, or $15.0 \mathrm{mg} / \mathrm{kg}$ i.p. cocaine. The results show that 


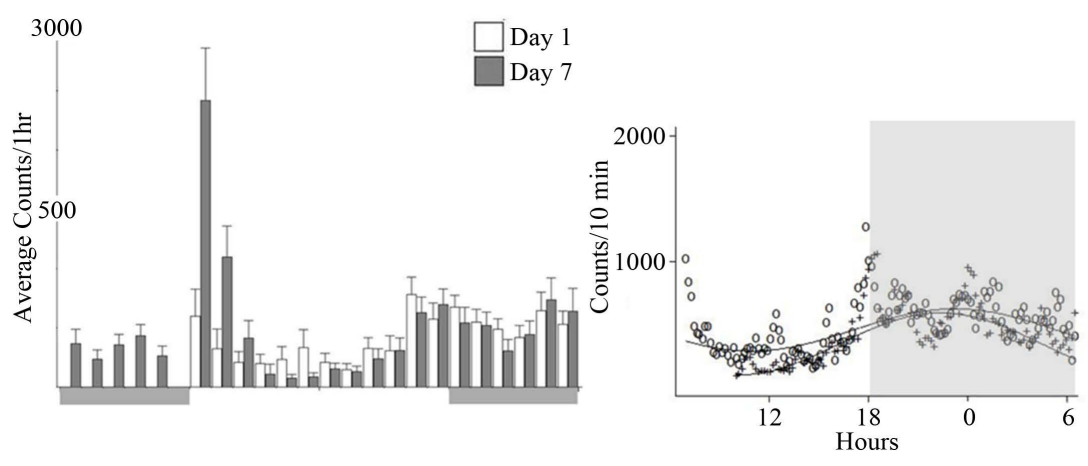

Figure 3. The hourly HA histograms and the corresponding temporal graph of the CCSA test of the $7.5 \mathrm{mg} / \mathrm{kg}$ cocaine group comparing ED 7 to ED 1 are displayed. ${ }^{\circ}$ symbol represents ED 1 and + symbol represents ED 2 in the CCSA graphs. The number on the $\mathrm{Y}$ axis represents the activity counts and the shaded line and area indicates that the recordings were at night.

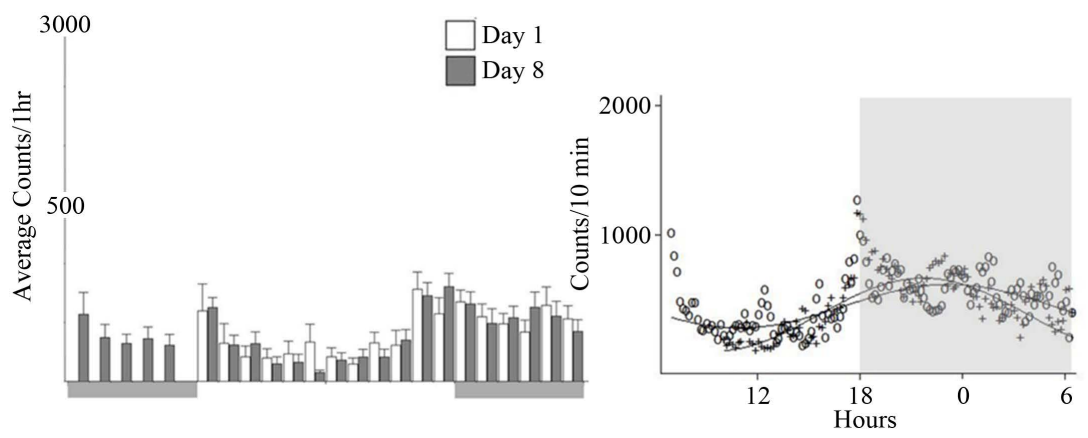

Figure 4. Shows the hourly HA histograms and the corresponding temporal graph of the CCSA test of the $7.5 \mathrm{mg} / \mathrm{kg}$ cocaine group comparing ED 8 to ED $1 .^{\circ}$ symbol represents ED 1 and + symbol represents ED 2 in the CCSA graphs. The number on the $\mathrm{Y}$ axis represents the activity counts and the shaded line and area indicates that the recordings were at night.

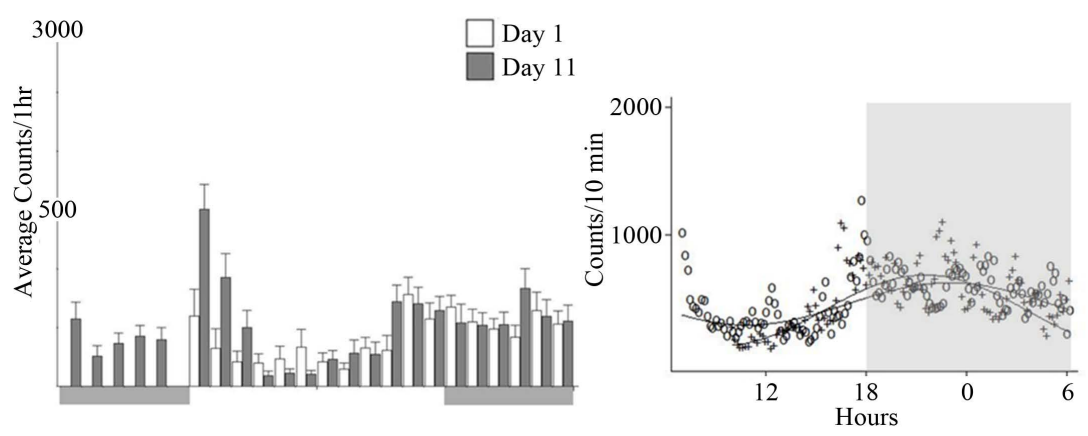

Figure 5. Compares the HA data of ED 1 to those of ED 11 for $7.5 \mathrm{mg} / \mathrm{kg}$ cocaine group. ${ }^{\circ}$ symbol represents ED 1 and + symbol represents ED 2 in the CCSA graphs.

all three doses of cocaine, $3.0 \mathrm{mg} / \mathrm{kg}, 7.5 \mathrm{mg} / \mathrm{kg}$, and $15.0 \mathrm{mg} / \mathrm{kg}$, but not saline injections, were able to alter the locomotor activity diurnal rhythm of female SD rats. These changes in circadian pattern were not due to the heightened locomotor activity levels observed two to three hours post cocaine administration, because the first three hours were excluded in all of the statistical analysis. [3] reported that numerous gene expressions, including many different circadian genes, are altered after self administration of cocaine into dorsal striatum. Although [3] did not examine locomotor activity level, these changes in circadian genes support the findings of present study. Other studies that did not focus on locomotor activity level have reported that repetitive cocaine admini- 
stration elicited significant changes in circadian gene expressions [9] [43] [44]. Changes in clockgene expression, which would alter the circadian activity patterns, suggests that the drug elicits long lasting effects. The findings of this study; showing that chronic cocaine exposure significantly alters the activity rhythmic pattern supports our hypothesis and are in agreement with result observed in the above study.

There is a strong influence by the circadian rhythms and genes on sensitization to drugs of abuse and drug seeking behaviors [4] [24] [42] [45]-[47]. For example, in mutant mice lacking mPer1 gene, no behavioral sensitization was observed after repeated cocaine administration, but mice with mPer2 mutation did exhibit hypersensitized response to cocaine in comparison to wild-type mice [42]. Practically all aspects of dopaminergic transmission involved in the actions of cocaine and other drugs of abuse in the brain are known to have a diurnal rhythm, including dopamine receptors and dopamine transporters [48]-[52]. Therefore, availability of these elements and the clock genes that control them are likely to be responsible for the diurnal differences in responsiveness to the psychostimulants. For instance, the greatest expression of behavioral sensitization to amphetamine is observed when amphetamine is administered during the dark phase [24] and for methylphenidate in the light phase [25].

[5] reported that the feeding patterns of SD male rats were significantly changed when $15.0 \mathrm{mg} / \mathrm{kg}$ cocaine was administered i.p. twice a day for nine days. Increased food intake during the light phase and reduced feeding during dark phase was observed. These subjects were individually housed, maintained on 12:12 light/dark cycle, and food and water were provided ad libitum. However, they did not observe any significant alterations in locomotor activity circadian pattern during these nine days. In present study, each group was exposed to repetitive $3.0 \mathrm{mg} / \mathrm{kg}, 7.5 \mathrm{mg} / \mathrm{kg}$, or $15.0 \mathrm{mg} / \mathrm{kg}$ cocaine administration and most of the groups exhibited significant changes in circadian locomotor pattern in all ED analyzed. The discrepancy between the two studies mentioned above may be due to differences in administration schedule, to different apparatus to measure the locomotor activity, to different method of data analysis, or to the fact that our subjects were female SD rats.

Some studies have suggested that female subjects tend to exhibit different degree of sensitization to the drug effect as compared to male subjects, because the drugs may interact with the reproductive cycle or the endogenous gonadal hormones [19] [53]. Indeed, there are reports showing that there are definite differences between the responses of female subjects and the responses of male subjects, human or rats, to cocaine and other psychostimulants [7] [54]-[57]. Adult female rats seem to be more sensitive to reinforcing effects of cocaine than male rats [3]. Furthermore, estradiol enhances cocaine intake as well [55]. Similarly, women seem to have an accelerated course to addiction taking less time to show symptoms of dependence after initial use [3] [58] [59]. Therefore, since females tend to be more sensitive to cocaine effects, difference between our study and [5] could be due to gender differences. However, many studies involving male rats have shown sensitization and gene expression alterations, so it is unlikely that the disparity between the two studies, our present study and the [5] study, are solely due to gender difference alone.

Can the daily repetitive cocaine exposure in this study be defined as "chronic treatment? It was reported that six daily injections of psychostimulant can be considered as chronic exposure [7] [27] for the following reason. Life expectancy of the average human in the Western country is about 78 years, and life expectancy of a rat is about 2 years. Six days are $0.82 \%$ of rat's life, and $0.82 \%$ of 78 human years is 233.5 days or 33.4 weeks. Therefore, six consecutive days of psychostimulant administration can be considered as a chronic treatment for rats. In this study, after the six daily injection and three days of washout, another treatment of the same dose was given, i.e. the animals were exposed to cocaine for a total of seven days over eleven day period, which can be considered as chronic exposure.

\section{Conclusion}

In conclusion, this study suggests that adult female SD rats chronically treated with cocaine exhibited significantly altered locomotor diurnal rhythm.

\section{Conflict of Interest}

The authors declare no conflicts of interest.

\section{Acknowledgements}

The authors would like to thank Catherine M. Claussen for her technical help. This study was supported in part 
by NIH R01 DA027222 grant.

\section{References}

[1] Haile, C.N., Kosten, T.R. and Kosten, T.A. (2009) Pharmacogenetic Treatments for Drug Addiction: Cocaine, Amphetamine and Methamphetamine. The American Journal of Drug and Alcohol Abuse, 35, 161-77. http://dx.doi.org/10.1080/00952990902825447

[2] Nikaido, T., Akiyama, M., Moriya, T. and Shibata, S. (2001) Sensitized Increase of Period Gene Expression in the Mouse Caudate/Putamen Caused by Repeated Injection of Methamphetamine. Molecular Pharmacology, 59, 894-900.

[3] Lynch, W.J. (2008) Acquisition and Maintenance of Cocaine Self-Administration in Adolescent Rats: Effects of Sex and Gonadal Hormones. Psychopharmacology (Berl), 197, 237-246. http://dx.doi.org/10.1007/s00213-007-1028-0

[4] McClung, C.A., Sidiropoulou, K., Vitaterna, M., Takahashi, J.S., White, F.J., Cooper, D.C. and Nestler, E.J. (2005) Regulation of Dopaminergic Transmission and Cocaine Reward by the Clock Gene. Proceedings of the National Academy of Sciences of the United States of America, 102, 9377-9381. http://dx.doi.org/10.1073/pnas.0503584102

[5] Giorgetti, M. and Zhdanova, I.V. (2000) Chronic Cocaine Treatment Induces Dysregulation in the Circadian Pattern of Rats’ Feeding Behavior. Brain Research, 877, 170-175. http://dx.doi.org/10.1016/S0006-8993(00)02671-8

[6] La Fleur, S.E., Kalsbeek, A., Wortel, J. and Buijs, R.M. (1999) A Suprachiasmatic Nucleus Generated Rhythm in Basal Glucose Concentrations. Journal of Neuroendocrinology, 11, 643-652. http://dx.doi.org/10.1046/j.1365-2826.1999.00373.x

[7] Lee, M.J., Yang, P.B., Wilcox, V.T., Burau, K.D., Swann, A.C. and Dafny, N. (2009) Does Repetitive Ritalin Injection Produce Long-Term Effects on SD Female Adolescent Rats? Neuropharmacology, 57, 201-207. http://dx.doi.org/10.1016/j.neuropharm.2009.06.008

[8] Reppert, S.M. and Weaver, D.R. (2002) Coordination of Circadian Timing in Mammals. Nature, 418, 935-941. http://dx.doi.org/10.1038/nature00965

[9] Manev, H. and Uz, T. (2006) Clock Genes: Influencing and Being Influenced by Psychoactive Drugs. Trends in Pharmacological Sciences, 27, 186-189. http://dx.doi.org/10.1016/j.tips.2006.02.003

[10] Schibler, U. and Sassone-Corsi, P. (2002) A Web of Circadian Pacemakers. Cell, 111, 919-922. http://dx.doi.org/10.1016/S0092-8674(02)01225-4

[11] Nakahata, Y., Akashi, M., Trcka, D., Yasuda, A. and Takumi, T. (2006) The in Vitro Real-Time Oscillation Monitoring System Identifies Potential Entrainment Factors for Circadian Clocks. BMC Molecular Biology, 7, 5. http://dx.doi.org/10.1186/1471-2199-7-5

[12] Johnson, C.H., Golden, S.S. and Kondo, T. (1998) Adaptive Significance of Circadian Programs in Cyanobacteria. Trends in Microbiology, 6, 407-410. http://dx.doi.org/10.1016/S0966-842X(98)01356-0

[13] Chou, T.C., Scammell, T.E., Gooley, J.J., Gaus, S.E., Saper, C.B. and Lu, J. (2003) Critical Role of Dorsomedial Hypothalamic Nucleus in a Wide Range of Behavioral Circadian Rhythms. The Journal of Neuroscience, 23, 10691-10702.

[14] Okamura, H., Yamaguchi, S. and Yagita, K. (2002) Molecular Machinery of the Circadian Clock in Mammals. Cell and Tissue Research, 309, 47-56. http://dx.doi.org/10.1007/s00441-002-0572-5

[15] Gallego, M. and Virshup, D.M. (2007) Post-Translational Modifications Regulate the Ticking of the Circadian Clock. Nature Reviews Molecular Cell Biology, 8, 139-148. http://dx.doi.org/10.1038/nrm2106

[16] Lowrey, P.L. and Takahashi, J.S. (2004) Mammalian Circadian Biology: Elucidating Genome-Wide Levels of Temporal Organization. Annual Review of Genomics and Human Genetics, 5, 407-441. http://dx.doi.org/10.1146/annurev.genom.5.061903.175925

[17] Iijima, M., Nikaido, T., Akiyama, M., Moriya, T. and Shibata, S. (2002) Methamphetamine-Induced, Suprachiasmatic Nucleus-Independent Circadian Rhythms of Activity and mPer Gene Expression in the Striatum of the Mouse. European Journal of Neuroscience, 16, 921-929. http://dx.doi.org/10.1046/j.1460-9568.2002.02140.x

[18] Askenasy, E.P., Taber, K.H., Yang, P.B. and Dafny, N. (2007) Methylphenidate (Ritalin): Behavioral Studies in the Rat. International Journal of Neuroscience, 117, 757-794. http://dx.doi.org/10.1080/00207450600910176

[19] Dafny, N. and Yang, P.B. (2006) The Role of Age, Genotype, Sex, and Route of Acute and Chronic Administration of Methylphenidate: A Review of Its Locomotor Effects. Brain Research Bulletin, 68, 393-405. http://dx.doi.org/10.1016/j.brainresbull.2005.10.005

[20] Algahim, M.F., Yang, P.B., Wilcox, V.T., Burau, K.D., Swann, A.C. and Dafny, N. (2009) Prolonged Methylphenidate Treatment Alters the Behavioral Diurnal Activity Pattern of Adult Male Sprague-Dawley Rats. Pharmacology, Biochemistry and Behavior, 92, 93-99. http://dx.doi.org/10.1016/j.pbb.2008.10.021

[21] Chelaru. M.I., Yang, P.B., and Dafny, N. (2012) Sex Difference in the Behavioral Response to Methylphenidate in 
Three Adolescent Rat Strains (WKY, SHR, SD). Behavioural Brain Research, 228, 8-17.

[22] Wilson, R.C., Vacek, T., Lanier, D.L. and Dewsbury, D.A. (1976) Open-Field Behavior in Muroid Rodents. Behavioral Biology, 17, 495-506. http://dx.doi.org/10.1016/S0091-6773(76)90901-9

[23] Gaytan, O., Ghelani, D., Martin, S., Swann, A. and Dafny, N. (1997) Methylphenidate: Diurnal Effects on Locomotor and Stereotypic Behavior in the Rat. Brain Research, 777, 1-12. http://dx.doi.org/10.1016/S0006-8993(97)00880-9

[24] Gaytan, O., Lewis, C., Swann, A. and Dafny, N. (1999) Diurnal Differences in Amphetamine Sensitization. European Journal of Pharmacology, 374, 1-9. http://dx.doi.org/10.1016/S0014-2999(99)00243-5

[25] Gaytan, O., Yang, P., Swann, A. and Dafny, N. (2000) Diurnal Differences in Sensitization to Methylphenidate. Brain Research, 864, 24-39. http://dx.doi.org/10.1016/S0006-8993(00)02117-X

[26] Yang, P.B., Amini, B., Swann, A.C. and Dafny, N. (2003) Strain Differences in the Behavioral Responses of Male Rats to Chronically Administered Methylphenidate. Brain Research, 971, 139-152. http://dx.doi.org/10.1016/S0006-8993(02)04240-3

[27] Yang, P.B., Swann, A.C. and Dafny, N. (2006) Acute and Chronic Methylphenidate Dose-Response Assessment on Three Adolescent Male Rat Strains. Brain Research Bulletin, 71, 301-310. http://dx.doi.org/10.1016/j.brainresbull.2006.09.019

[28] Dafny, N. and Terkel, J. (1990) Hypothalamic Neuronal Activity Associated with Onset of Pseudo Pregnancy in the Rat. Neuroendocrinology, 51, 459-467. http://dx.doi.org/10.1159/000125375

[29] Bingham, C., Arbogas, A. and Guillaume, B. (1982) Influential Statistical Methods for Estimating and Comparing Cosine Parameters. Chronobiologia, 9, 397-439.

[30] Robinson, T.E. and Becker, J.B. (1986) Enduring Changes in Brain and Behavior Produced by Chronic Amphetamine Administration: A Review and Evaluation of Animal Models of Amphetamine Psychosis. Brain Research, 396, 157198. http://dx.doi.org/10.1016/0165-0173(86)90002-0

[31] Vanderschuren, L.J. and Kalivas, P.W. (2000) Alterations in Dopaminergic and Glutamatergic Transmission in the Induction and Expression of Behavioral Sensitization: A Critical Review of Preclinical Studies. Psychopharmacology, 151, 99-120. http://dx.doi.org/10.1007/s002130000493

[32] King, L.N., Dafny, N., Yang, P.B. and Swann, A.C. (2009) Does a Rat's Exposure to Cocaine during Adolescence Affect Its Response to Cocaine in Adulthood? International Journal of Neuroscience, 119, 879-907. http://dx.doi.org/10.1080/00207450701591016

[33] Mattson, B.J., Koya, E., Simmons, D.E., Mitchell, T.B., Berkow, A., Crombag, H.S. and Hope, B.T. (2008) ContextSpecific Sensitization of Cocaine-Induced Locomotor Activity and Associated Neuronal Ensembles in Rat Nucleus Accumbens. European Journal of Neuroscience, 27, 202-212. http://dx.doi.org/10.1111/j.1460-9568.2007.05984.x

[34] Valjent, E., Bertran-Gonzalez, J., Aubier, B., Greengard, P., Hervé, D. and Girault, J.A. (2010) Mechanisms of Locomotor Sensitization to Drugs of Abuse in a Two-Injection Protocol. Neuropsychopharmacology, 35, 401-415. http://dx.doi.org/10.1038/npp.2009.143

[35] Kuhar, M.J., Ritz, M.C. and Boja, J.W. (1991) The Dopamine Hypothesis of the Reinforcing Properties of Cocaine. Trends in Neurosciences, 14, 299-302. http://dx.doi.org/10.1016/0166-2236(91)90141-G

[36] Chen, J.C., Chen, P.C. and Chiang, Y.C. (2009) Molecular Mechanisms of Psychostimulant Addiction. Chang Gung Medical Journal, 32, 148-154.

[37] Drago, J., Gerfen, C.R., Westphal, H. and Steiner, H. (1996) D1 Dopamine Receptor-Deficient Mouse: Cocaine-Induced Regulation of Immediate-Early Gene and Substance P Expression in the Striatum. Neuroscience, 74, 813-823. http://dx.doi.org/10.1016/0306-4522(96)00145-5

[38] Hyman, S.E. and Malenka, R.C. (2001) Addiction and the Brain: The Neurobiology of Compulsion and Its Persistence. Nature Reviews Neuroscience, 2, 695-703. http://dx.doi.org/10.1038/35094560

[39] Neisewander, J.L., Fuchs, R.A., O’Dell, L.E. and Khroyan, T.V. (1998) Effects of SCH23390 on Dopamine D1 Receptor Occupancy and Locomotion Produced by Intraaccumbens Cocaine Infusion. Synapse, 30, 194-204. http://dx.doi.org/10.1002/(SICI)1098-2396(199810)30:2<194::AID-SYN9>3.0.CO;2-7

[40] Nestler, E.J. (2004) Molecular Mechanisms of Drug Addiction. Neuropharmacology, 47, $24-32$. http://dx.doi.org/10.1016/j.neuropharm.2004.06.031

[41] Nishi, A., Bibb, J.A., Snyder, G.L., Higashi, H., Nairn, A.C. and Greengard, P. (2000) Amplification of Dopaminergic Signaling by a Positive Feedback Loop. Proceedings of the National Academy of Sciences of the United States of America, 97, 12840-12845. http://dx.doi.org/10.1073/pnas.220410397

[42] Abarca, C., Albrecht, U. and Spanagel, R. (2002) Cocaine sensitization and reward are under the influence of circadian genes and rhythm. Proceedings of the National Academy of Sciences of the United States of America, 99, 9026-9030. http://dx.doi.org/10.1073/pnas.142039099 
[43] Uz, T., Ahmed, R., Akhisaroglu, M., Kurtuncu, M., Imbesi, M., Dirim Arslan, A. and Manev, H. (2005) Effect of Fluoxetine and Cocaine on the Expression of Clock Genes in the Mouse Hippocampus and Striatum. Neuroscience, 134, 1309-1316. http://dx.doi.org/10.1016/j.neuroscience.2005.05.003

[44] Perreau-Lenz, S. and Spanagel, R. (2008) The Effects of Drugs of Abuse on Clock Genes. Drug News \& Perspectives, 21, 211-217. http://dx.doi.org/10.1358/dnp.2008.21.4.1213350

[45] Sleipness, E.P., Sorg, B.A. and Jansen, H.T. (2005) Time of Day Alters Long-Term Sensitization to Ocaine in Rats. Brain Research, 1065, 132-137. http://dx.doi.org/10.1016/j.brainres.2005.10.017

[46] Imbesi, M., Yildiz, S., Dirim Arslan, A., Sharma, R., Manev, H. and Uz, T. (2009) Dopamine Receptor-Mediated Regulation of Neuronal “Clock” Gene Expression. Neuroscience, 158, 537-544. http://dx.doi.org/10.1016/j.neuroscience.2008.10.044

[47] Yuferov, V., Butelman, E.R. and Kreek, M.J. (2005) Biological Clock: Biological Clocks May Modulate Drug Addiction. European Journal of Human Genetics, 13, 1101-1103. http://dx.doi.org/10.1038/sj.ejhg.5201483

[48] Weber, M., Lauterburg, T., Tobler, I. and Burgunder, J.M. (2004) Circadian Patterns of Neurotransmitter Related Gene Expression in Motor Regions of the Rat Brain. Neuroscience Letters, 358, 17-20. http://dx.doi.org/10.1016/j.neulet.2003.12.053

[49] Schade, R., Vick, K., Ott, T., Sohr, R., Pfister, C., Bellach, J., Golor, G. and Lemmer, B. (1995) Circadian Rhythms of Dopamine and Cholecystokinin in Nucleus Accumbens and Striatum of Rats-Influence on Dopaminergic Stimulation. Chronobiology International, 12, 87-99. http://dx.doi.org/10.3109/07420529509064504

[50] Jones, C.G., Yang, P.B., Wilcox, V.T., Barau, K.D. and Dafny, N. (2014) Acute and Chronic Psychostimulant Treatment Modulate the Diurnal Rhythm Activity Pattern of WKY Female Adolescent Rats. Journal of Neural Transmission, 121, 457-468.

[51] Sleipness, E.P., Sorg, B.A. and Jansen, H.T. (2007) Diurnal Differences in Dopamine Transporter and Tyrosine Hydroxylase Levels in Rat Brain: Dependence on the Suprachiasmatic Nucleus. Brain Research, 1129, 34-42. http://dx.doi.org/10.1016/j.brainres.2006.10.063

[52] Akhisaroglu, M., Kurtuncu, M., Manev, H. and Uz, T. (2005) Diurnal Rhythms in Quinpirole-Induced Locomotor Behaviors and Striatal D2/D3 Receptor Levels in Mice. Pharmacology, Biochemistry and Behavior, 80, 371-377. http://dx.doi.org/10.1016/j.pbb.2004.11.016

[53] Camp, D.M. and Robinson, T.E. (1988) Susceptibility to Sensitization. II. The Influence of Gonadal Hormones on Enduring Changes in Brain Monoamines and Behavior Produced by the Repeated Administration of D-Amphetamine or Restraint Stress. Behavioural Brain Research, 30, 69-88. http://dx.doi.org/10.1016/0166-4328(88)90009-5

[54] Becker, J.B. and Hu, M. (2008) Sex Differences in Drug Abuse. Frontiers in Neuroendocrinology, 29, 36-47. http://dx.doi.org/10.1016/j.yfrne.2007.07.003

[55] Zhao, W. and Becker, J.B. (2009) Sensitization Enhances Acquisition of Cocaine Self-Administration in Female Rats: Estradiol Further Enhances Cocaine Intake after Acquisition. Hormones and Behavior, 58, 8-12.

[56] Becker, J.B., Molenda, H. and Hummer, D.L. (2001) Gender Differences in the Behavioral Response to Cocaine and Amphetamine. Implications for Mechanisms Mediating Gender Differences in Drug Abuse. Annals of the New York Academy of Sciences, 937, 172-187. http://dx.doi.org/10.1111/j.1749-6632.2001.tb03564.x

[57] Griffin, M.L., Weiss, R.D., Mirin, S.M. and Lange, U. (1989) A Comparison of Male and Female Cocaine Abusers. Archives of General Psychiatry, 46, 122-126. http://dx.doi.org/10.1001/archpsyc.1989.01810020024005

[58] Brecht, M.L., O’Brien, A., von Mayrhauser, C. and Anglin, M.D. (2004) Methamphetamine Use Behaviors and Gender Differences. Addictive Behaviors, 29, 89-106. http://dx.doi.org/10.1016/S0306-4603(03)00082-0

[59] Hernandez-Avila, C.A., Rounsaville, B.J. and Kranzler, H.R. (2004) Opioid-, Cannabis- and Alcohol-Dependent Women Show More Rapid Progression to Substance Abuse Treatment. Drug and Alcohol Dependence, 74, $265-272$. http://dx.doi.org/10.1016/j.drugalcdep.2004.02.001 
Scientific Research Publishing (SCIRP) is one of the largest Open Access journal publishers. It is currently publishing more than 200 open access, online, peer-reviewed journals covering a wide range of academic disciplines. SCIRP serves the worldwide academic communities and contributes to the progress and application of science with its publication.

Other selected journals from SCIRP are listed as below. Submit your manuscript to us via either submit@scirp.org or Online Submission Portal.
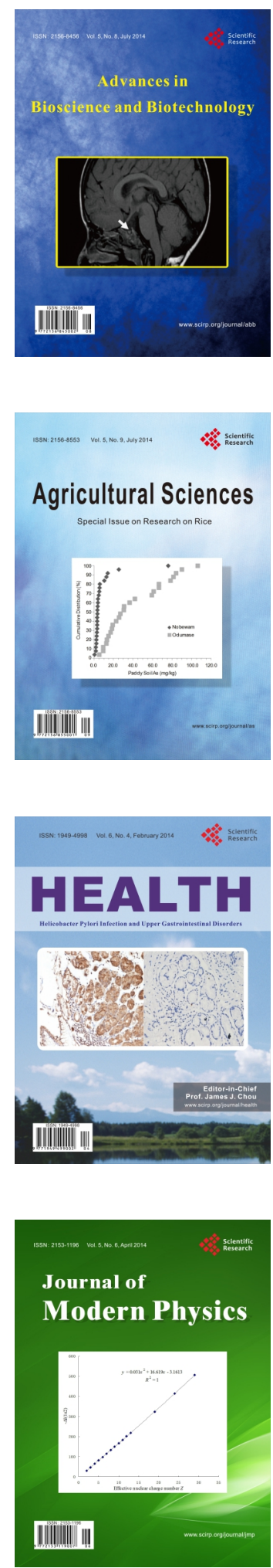
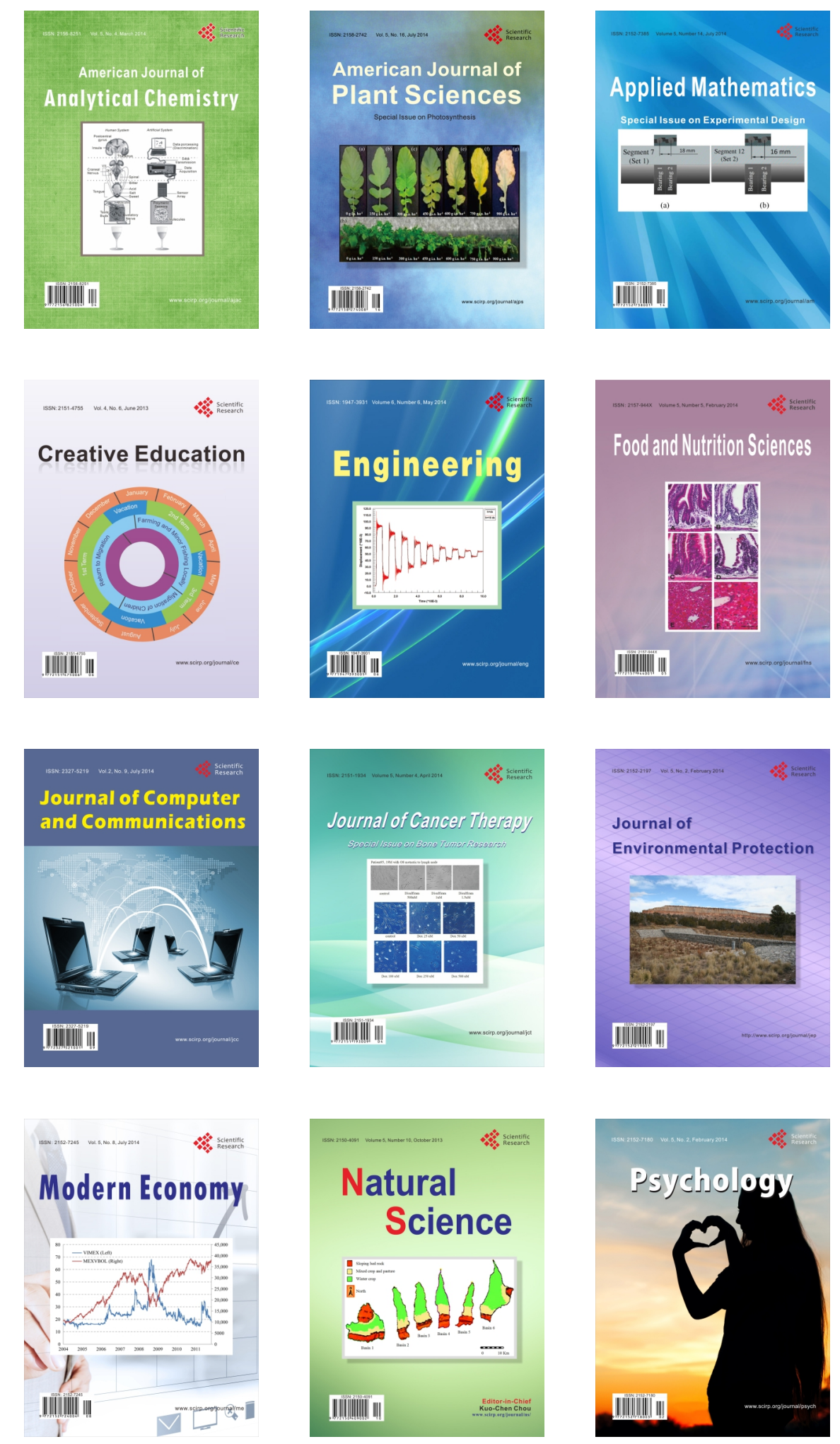